\title{
Molecular Cytogenetic Applications in Analysis of the Cancer Genome
}

\author{
Pulivarthi H. Rao, Subhadra V. Nandula, and Vundavalli V. Murty
}

\begin{abstract}
Summary
Cancer cells exhibit nonrandom and complex chromosome abnormalities. The role of genomic changes in cancer is well established. However, the identification of complex and cryptic chromosomal changes is beyond the resolution of conventional banding methods. The fluorescence microscopy afforded by imaging technologies, developed recently, facilitates a precise identification of these chromosome alterations in cancer. The three most commonly utilized molecular cytogenetics methods comparative genomic hybridization, spectral karyotype, and fluorescence in situ hybridization, that have already become benchmark tools in cancer cytogenetics, are described in this chapter. Comparative genomic hybridization is a powerful tool for screening copy-number changes in tumor genomes without the need for preparation of metaphases from tumor cells. Multicolor spectral karyotype permits visualization of all chromosomes in one experiment permitting identification of precise chromosomal changes on metaphases derived from tumor cells. The uses of fluorescence in situ hybridization are diverse, including mapping of alteration in single copy genes, chromosomal regions, or entire chromosomes. The opportunities to detect genetic alterations in cancer cells continue to evolve with the use of these methodologies both in diagnosis and research.
\end{abstract}

Key Words: Cancer; chromosome aberrations; comparative genomic hybridization; fluorescence in situ hybridization; spectral karyotyping; molecular cytogenetics.

\section{Introduction}

The cancer cell accumulates a number of genetic changes during the process of tumor initiation and progression. In order to understand the fundamental biology of cancer, it is essential to identify as many of these genetic alterations during cancer development as possible. Theodor Boveri's hypothesis in 1914 that chromosome abnormalities play a central role in transformation of normal cell to neoplastic cell laid the foundation for the 
current understanding of chromosomal basis of cancer. Therefore, it is critical to identify chromosomal changes in the tumor genome to accrue knowledge of molecular mechanisms of the neoplastic process.

Conventional cytogenetic analysis is one of the most widely accepted DNA genome-screening tools for identification of chromosomal aberrations in cancer cells. However, there are two built-in limitations to conventional cytogenetic analysis. One limitation is representation. The success rate of detection of clonally abnormal karyotypes in short-term cultures of most types of tumors is low. Such a low cytogenetic success rate introduces a bias in representation of true genetic aberration in the tumor genome. The other limitation is complexity. In addition to recognizable chromosomal aberrations, most tumors exhibit marker chromosomes whose derivation is difficult to determine by conventional cytogenetic analysis, which introduces another level of bias. To overcome these limitations a host of molecular cytogenetic techniques such as fluorescence in situ hybridization (FISH), comparative genomic hybridization (CGH), multicolor spectral karyotype (SKY)/multicolor FISH (m-FISH), and array-based CGH have recently been developed (1-9). In this chapter, detailed methodologies and limitations of three of the most commonly used molecular cytogenetic methods in the analysis of the cancer genome are discussed (Table 1).

\section{Materials}

\subsection{Preparation of Human Lymphocyte Metaphase Chromosomes}

1. RPMI medium 1640 (GIBCO, Invitrogen, Carlsbad, CA; cat. no. 21870-076).

2. L-Glutamine $200 \mathrm{mM}$ (GIBCO, cat. no. 25030-081), $100 \mathrm{~mL}$ (make 5-mL aliquots; add 5-500 mL medium).

3. Penicillin/streptomycin (GIBCO, cat. no. 15070-063) (make 5-mL aliquots; add 5-500 mL medium).

4. Fetal bovine serum qualified, heat inactivated (GIBCO, cat. no. 16140-071).

5. Phytohaemagglutinin (PHA) lyophilized (GIBCO, cat. no. 10576-015). (Rehydrate with $10 \mathrm{~mL}$ of sterile double-distilled $[\mathrm{dd}] \mathrm{H}_{2} \mathrm{O}$ and store at $\left[20^{\circ} \mathrm{C}\right]$.)

6. Colcemid, KaryoMAX Colcemid (10 $\mu \mathrm{g} / \mathrm{mL})$ (GIBCO, cat. no. 15210-040).

\subsection{Preparation of Labeled DNA Probes for CGH}

1. 10X Nucleotide mix (see item 31).

2. $25 \mu M$ dTTP (Roche Diagnostics, Indianapolis, IN; cat. no. 105 1482).

3. $25 \mu M$ dATP (Roche Diagnostics, cat. no. 105 1440).

4. $25 \mu M$ dGTP (Roche Diagnostics, cat. no. 105 1466).

5. $25 \mu M \mathrm{dCTP}$ (Roche Diagnostics, cat. no. 105 1458).

6. Fluorescein 12-dUTP (Dupont NEN, Boston, MA; cat. no. NEL-413).

7. Texas Red 5-dUTP (Dupont NEN, cat. no. NEL-417).

8. DNA polymerase I ( $0.5 \mathrm{U} / \mu \mathrm{L} / 0.4 \mathrm{mU} / \mu \mathrm{L}$ DNase I) (Invitrogen, cat. no. 18162016).

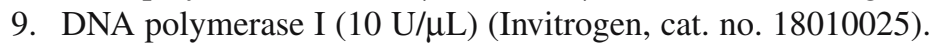


Table 1

\section{Advantages and Limitations of Various Molecular Cytogenetic Techniques}

\begin{tabular}{|c|c|c|}
\hline $\begin{array}{l}\text { Fluorescent in situ } \\
\text { hybridization (FISH) }\end{array}$ & $\begin{array}{l}\text { Comparative genomic } \\
\text { hybridization }(\mathrm{CGH})\end{array}$ & $\begin{array}{c}\text { Spectral karyotyping } \\
\text { (SKY) }\end{array}$ \\
\hline \multicolumn{3}{|l|}{ Advantages } \\
\hline $\begin{array}{l}\text { Highly specific } \\
\text { and sensitive }\end{array}$ & $\begin{array}{l}\text { Global view of chromosomal } \\
\text { losses, gains, and } \\
\text { amplifications }\end{array}$ & $\begin{array}{l}\text { Detects complex and } \\
\text { cryptic chromosomal } \\
\text { translocations }\end{array}$ \\
\hline $\begin{array}{l}\text { Mapping of genes } \\
\text { to chromosomes }\end{array}$ & $\begin{array}{l}\text { No need for chromosomes } \\
\text { from clinical samples and } \\
\text { requires only a small } \\
\text { amount of DNA }(\sim 2 \mu \mathrm{g})\end{array}$ & $\begin{array}{l}\text { Defines the origin of } \\
\text { markers, hsrs and double } \\
\text { minute chromosomes. } \\
\text { Sensitive to detect } \\
\text { deletions } 10 \text { to } 15 \mathrm{mb}\end{array}$ \\
\hline $\begin{array}{l}\text { Detects deletions, } \\
\text { inversions, } \\
\text { numerical changes, } \\
\text { and translocations } \\
\text { in interphase nuclei } \\
\text { and metaphase } \\
\text { chromosomes }\end{array}$ & $\begin{array}{l}\text { Sensitive to detect deletions } \\
10-15 \mathrm{mb}\end{array}$ & $\begin{array}{l}\text { Detects the chromosomal } \\
\text { boundaries in } \\
\text { interphase nuclei }\end{array}$ \\
\hline \multicolumn{3}{|l|}{$\begin{array}{l}\text { Sensitive to detect } \\
\text { deletions }>1 \mathrm{~kb}\end{array}$} \\
\hline \multicolumn{3}{|l|}{ Limitations } \\
\hline $\begin{array}{l}\text { Highly focused, prior } \\
\text { knowledge of } \\
\text { gene(s) is } \\
\text { required }\end{array}$ & $\begin{array}{l}\text { Unable to detect balanced } \\
\text { translocations and } \\
\text { inversions } \\
\text { Detects abnormalities only } \\
\text { if the tumor cells are } \\
\text { greater than } 50 \% \text { of } \\
\text { the specimen }\end{array}$ & $\begin{array}{l}\text { Cannot detect inversions } \\
\text { and duplications of } \\
\text { specific band(s) and } \\
\text { subtle deletions }\end{array}$ \\
\hline
\end{tabular}

10. DNase I type II (Sigma, St. Louis, MO; cat. no. D4527).

11. 2-Mercaptoethanol (Sigma, cat. no. M6250).

12. Agarose (Sigma, cat. no. A9539).

13. G-50 Sephadex columns (Roche Diagnostics, cat. no. 1523023).

14. Pepsin (Sigma, cat. no. P6887).

15. Human Cot-1 DNA (Invitrogen, cat. no. 15279-011).

16. Lambda DNA/Hind III marker (Promega, Madison, WI; cat. no. G1711).

17. Formamide (Fisher, cat. no. F84-1).

18. 4',6-diamidino-2-phenylindole (DAPI) (Sigma, cat. no. D-9542).

19. VECTASHIELD mounting medium (Vector Laboratories, Burlingame, CA; cat. no. $\mathrm{H}-1000)$.

20. Diamond pencil.

21. Humidifier boxes. 
22. Rubber sealant.

23. Water baths $\left(37,45\right.$, and $\left.75^{\circ} \mathrm{C}\right)$.

24. Circulating water bath $\left(15^{\circ} \mathrm{C}\right)$ or PCR thermal cycler.

25. Glass slides, $22-\mathrm{mm}^{2}$ and $24 \times 50-\mathrm{mm}^{2}$ cover slips.

26. Vertical Coplin jars.

27. DAPI Stock solution $(100 \mu \mathrm{g} / \mathrm{mL})$ :

a. Dissolve $1 \mathrm{mg}$ DAPI in $10 \mathrm{~mL}$ of $\mathrm{ddH}_{2} \mathrm{O}$. Add few drops of methanol to dissolve DAPI before adding $\mathrm{ddH}_{2} \mathrm{O}$. Store at $-20^{\circ} \mathrm{C}$.

b. Working solution: add $1-2 \mu \mathrm{L}$ of DAPI stock solution to $1 \mathrm{~mL}$ of antifade mounting medium (VECTASHIELD mounting medium). Aliquot into small brown tubes and store at $-20^{\circ} \mathrm{C}$.

28. Denaturation solution ( $\mathrm{pH} 7.0)$ :
a. $350 \mathrm{~mL}$ Formamide.
b. $50 \mathrm{~mL} 20 \mathrm{X}$ SSC.
c. $100 \mathrm{~mL} \mathrm{ddH} \mathrm{H}_{2} \mathrm{O}$.
d. Stir well and adjust pH to 7.0 if necessary with $1 \mathrm{~N} \mathrm{HCl}$. Store at $4^{\circ} \mathrm{C}$.

29. DNase working solution:

a. Stock solution: dissolve $3 \mathrm{mg}$ of DNase in $1 \mathrm{~mL}$ of $0.15 \mathrm{M} \mathrm{NaCl}$ and $50 \%$ glycerol. Aliquot $100-\mu \mathrm{L}$ volumes into small tubes and store at $-20^{\circ} \mathrm{C}$.

b. Working solution: add $1 \mu \mathrm{L}$ stock solution to ice cold $500 \mu \mathrm{LddH}_{2} \mathrm{O}$ immediately before use, discard after each use (see Note 1).

30. Master hybridization buffer ( $\mathrm{pH} 7.0)$ :
a. $5 \mathrm{~mL}$ Formamide.
b. $1 \mathrm{~mL} 20 \mathrm{X}$ SSC.
c. 1 gm Dextran sulfate.
d. Make up to $10 \mathrm{~mL}$ with $\mathrm{ddH}_{2} \mathrm{O}$.
e. Filter through $0.22-\mu$ filter and store at $-20^{\circ} \mathrm{C}$.

31. 10X Nucleotide mix:
a. $100 \mu \mathrm{L} 10 \mathrm{~m} M$ dATP.
b. $100 \mu \mathrm{L} 10 \mathrm{~m} M$ dGTP.
c. $100 \mu \mathrm{L} 10 \mathrm{~m} M \mathrm{dCTP}$.
d. $2.5 \mathrm{~mL}$ Tris- $\mathrm{HCl}(\mathrm{pH} 7.2)$.
e. $250 \mu \mathrm{L} 1 M \mathrm{MgCl}_{2}$.
f. $34 \mu \mathrm{L}$ 14.7 M 2-Mercaptoethanol.
g. $50 \mu \mathrm{L} 10 \mathrm{mg} / \mathrm{mL}$ Bovine serum albumin.

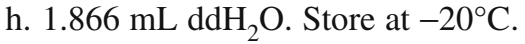

32. Pepsin:
a. Stock solution $(10 \%)=100 \mathrm{mg} / \mathrm{mL}$, dissolve in sterile water, make $50-\mu \mathrm{L}$ aliquots, store at $-20^{\circ} \mathrm{C}$. Mix $20 \mu \mathrm{L}$ pepsin in $100 \mathrm{~mL}$ prewarmed $0.01 N \mathrm{HCl}$ and adjust $\mathrm{pH}$ to 2.0 . Incubate slides at $37^{\circ} \mathrm{C}$ for $5-10 \mathrm{~min}$ and wash slides in $1 \mathrm{X}$ PBS and $1 \mathrm{X} \mathrm{PBS} / \mathrm{MgCl}_{2}$ Store at $-20^{\circ} \mathrm{C}$.

33. Washing solution ( $\mathrm{pH} 7.0)$ :
a. $250 \mathrm{~mL}$ Formamide.
b. $50 \mathrm{~mL} 20 \mathrm{X}$ Saline sodium citrate (SSC). 
c. $200 \mathrm{~mL} \mathrm{ddH_{2 }} \mathrm{O}$.

d. Stir well and adjust $\mathrm{pH}$ to 7.0 if necessary with $0.1 \mathrm{~N} \mathrm{HCl}$. Store at $4^{\circ} \mathrm{C}$.

34. Common stock solutions (10):

a. $3 M$ Sodium acetate $\mathrm{pH}$ 5.2. Dissolve $408.1 \mathrm{~g}$ of sodium acetate $3 \mathrm{H}_{2} \mathrm{O}$ in $800 \mathrm{~mL}$ of $\mathrm{H}_{2} \mathrm{O}$. Adjust the $\mathrm{pH}$ to 5.2 with glacial acetic acid and sterilize by autoclaving.

b. PBS. Add $8 \mathrm{~g} \mathrm{NaCl}, 200 \mathrm{mg} \mathrm{KCl}, 1.44 \mathrm{~g} \mathrm{Na}_{2} \mathrm{HPO}_{4}$ (dibasic, anhydrous), and $240 \mathrm{mg} \mathrm{K \textrm {K } _ { 2 }} \mathrm{PO}_{4}$ (monobasic, anhydrous) to $1 \mathrm{~L} \mathrm{H}_{2} \mathrm{O}$ and adjust $\mathrm{pH}$ using $\mathrm{HCl}$. Sterilize by autoclaving.

c. $5 \mathrm{M}$ Sodium chloride. Dissolve $292.2 \mathrm{~g}$ of $\mathrm{NaCl}$ in $800 \mathrm{~mL}$ of $\mathrm{H}_{2} \mathrm{O}$; adjust volume to $1 \mathrm{~L}$ with $\mathrm{H}_{2} \mathrm{O}$. Sterilize by autoclaving.

d. 20X SCC. Dissolve $175.3 \mathrm{~g}$ of $\mathrm{NaCl}$ and $88.2 \mathrm{~g}$ of sodium citrate in $800 \mathrm{~mL}$ $\mathrm{H}_{2} \mathrm{O}$. Adjust the $\mathrm{pH}$ to 7.0 with $\mathrm{NaOH}$ and make up to $1 \mathrm{~L}$ with $\mathrm{H}_{2} \mathrm{O}$. Sterilize by autoclaving.

e. $1 M$ Tris- $\mathrm{HCl}$, $\mathrm{pH}$ 7.2. Add $121 \mathrm{~g}$ of Tris base to $900 \mathrm{~mL} \mathrm{H}_{2} \mathrm{O}$. Adjust $\mathrm{pH}$ to 7.2 by adding $76 \mathrm{~mL}$ of $\mathrm{HCl}$ and adjust the volume to $1 \mathrm{~L}$ with $\mathrm{H}_{2} \mathrm{O}$. Sterilize by autoclaving.

f. Nonidet P-40-sodium bicarbonate buffer $(\mathrm{PN})$ buffer $(\mathrm{pH}$ 8.0): add $1 \mathrm{~g}$ sodium bicarbonate and $5 \mathrm{~mL}$ of Nonidet P-40 to $900 \mathrm{~mL}-\mathrm{dH}_{2} \mathrm{O}$. Stir well and store at $4^{\circ} \mathrm{C}$.

\subsection{Tumor Chromosome Preparations for SKY and FISH}

1. RPMI medium 1640 (GIBCO, cat. no. 21870-076).

2. L-Glutamine $200 \mathrm{mM}$ (GIBCO, cat. no. 25030-081), $100 \mathrm{~mL}$ (make 5-mL aliquots; add $5-500 \mathrm{~mL}$ medium).

3. Penicillin/streptomycin (GIBCO, cat. no. 15070-063) (make 5-mL aliquots; add $5-500 \mathrm{~mL}$ medium).

4. Fetal bovine serum qualified, heat inactivate (GIBCO, cat. no. 16140-071).

5. Colcemid, KaryoMAX Colcemid (10 $\mu \mathrm{g} / \mathrm{mL})$ (GIBCO, cat. no. 15210-040).

\subsection{Spectral Karyotyping}

1. Formamide (Fisher, Pittsburg, PA; cat. no. F84-1).

2. DAPI (Sigma, cat. no. D-9542).

3. VECTASHIELD mounting medium (Vector Laboratories, H-1000).

4. Diamond pencil.

5. Humidifier boxes.

6. Rubber sealant.

7. Water baths $\left(37,45\right.$, and $\left.75^{\circ} \mathrm{C}\right)$.

8. Formaldehyde (Sigma, cat. no. F1268).

9. Glass slides, $22-\mathrm{mm}^{2}$ and $24 \times 50-\mathrm{mm}^{2}$ cover slips.

10. Pepsin (Sigma, cat. no. P6887).

11. 1X PBS (Invitrogen, cat. no. 20012-027).

12. $1 \mathrm{M} \mathrm{MgCl}_{2}$ (Sigma, cat. no. M-1028).

13. PBD (PBS + Tween-20).

14. Human spectral karyotyping reagent (Applied Spectral Imaging, Visa, CA; cat. no. SKY 000029). 
15. Mouse spectral karyotyping reagent (Applied Spectral Imaging, cat. no. SKY 000031).

16. Concentrated antibodies detection kit (CAD) (Applied Spectral Imaging, cat. no. SKY 000133).

17. Tween-20 (Sigma, cat. no. P 5927).

18. $0.01 M \mathrm{HCl}: 1 \mathrm{~mL} 1 M \mathrm{HCl}$ in $99 \mathrm{~mL} \mathrm{dH_{2 }}$. Prewarm to $37^{\circ} \mathrm{C}$.

19. $4 \mathrm{X} \mathrm{SSC} /$ Tween-20: add $100 \mathrm{~mL} 20 \mathrm{X} \mathrm{SSC}$ and $0.5 \mathrm{~mL}$ Tween- 20 in $400 \mathrm{~mL} \mathrm{dH}_{2} \mathrm{O}$ and heat for $30 \mathrm{~min}$ at $45^{\circ} \mathrm{C}$.

20. $\mathrm{PBS} / \mathrm{MgCl}_{2}$ : add $50 \mathrm{~mL} 1 \mathrm{M} \mathrm{MgCl}_{2}$ to $950 \mathrm{~mL} \mathrm{dH} \mathrm{H}_{2} \mathrm{O}$.

21. $1 \%$ Formaldehyde: add $2.7 \mathrm{~mL}$ of $37 \%$ formaldehyde to $100 \mathrm{~mL} \mathrm{PBS} / \mathrm{MgCl}_{2}$.

22. Pepsin stock:

a. See for details Subheading 2.2., item 32 .

23. Denaturation solution ( $\mathrm{pH} 7.0)$ :

a. See for details Subheading 2.2., item 28.

24. Washing solution ( $\mathrm{pH} 7.0$ ):

a. See for details Subheading 2.2., item 33 .

\subsection{Preparation of Labeled DNA Probes for FISH}

1. Spectrum Green-dUTP (50 nM) (Vysis, Des Plaines, IL; cat. no. 30-803200).

2. Spectrum Red-dUTP (50 nM) (Vysis, cat. no. 30-803400).

3. For other materials please refer to Subheading 2.2.

\section{Methods}

\subsection{Comparative Genomic Hybridization}

1. CGH is used in delineating chromosomal gains, losses, and amplifications of a tumor genome by mapping these changes to a normal metaphase. CGH is based on the competitive hybridization of differentially labeled normal (reference) and tumor (test) DNA (1,11). The standard direct labeling protocol uses normal and tumor DNA that has been labeled by incorporation of flurochrome-conjugated nucleotides. An alternative method involves a slightly different procedure using normal and tumor DNA that have been labeled with biotin or dioxigenin. This latter method requires additional steps for detecting these labels with fluorochrome-conjugated secondary agents. The repetitive sequences present in both genomes are suppressed by adding an excess of unlabeled Cot-1 DNA to the hybridization mixture or coprecipitating with the differentially labeled tumor and normal genomic DNA. Hybridized probes are detected with different colored fluorochromes (e.g., red and green). The ratio of green to red fluorescence intensities along the length of the chromosome reflects the relative amounts of DNA sequences in the test DNA. Measuring the ratio of color intensities along the length of the chromosomes will provide DNA copy number changes in the tumor genome. The labeled normal DNA included in the hybridization process serves as a control for regional variations in the ability to hybridize to the target chromosomes.

2. Although high-level amplifications are visible directly in a fluorescence microscope, a quantitative measurement of fluorescence intensity values based on digital image 
analysis is crucial for a precise estimate of low copy-number changes. This analysis includes image acquisition of a green and red fluorescence with a charge-coupled device (CCD) camera. Using custom computer software, the painted chromosomes are then segmented and the florescence values determined perpendicular to the axis of the chromosome on a pixel-to-pixel basis. The result of measurement of the fluorescence values can now be visualized by means of a value table where certain colors refer to gains or losses in the tumor genome. The final step in a quantitative fluorescence measurement includes the calculation of average ratio profiles along the chromosomal axis based on data from a minimum of 10 chromosomes ( 5 metaphase spreads). The average ratio of 1.0 indicates equal copy numbers of the respective chromosomes, a ratio of 0.5 indicates a deletion of one homologue and a ratio of 1.5 reflects a trisomy in the genome. Gene amplification can be visualized as a peak fluorescence ratio of $>2.0$ and a localized signal to specific chromosome bands.

\subsection{Preparation of Human Lymphocyte Metaphase Chromosomes}

1. Prewarm $40 \mathrm{~mL}$ RPMI 1640 medium containing $20 \%$ fetal bovine serum (FBS), $1 \%$ L-glutamine, and $1 \%$ penicillin/streptomycin. Add $400 \mu \mathrm{L}$ of PHA to the medium.

2. Collect $10 \mathrm{~mL}$ of whole blood in a heparin tube (green top).

3. Spin $10 \mathrm{~mL}$ of blood at $250 \mathrm{~g}(1500 \mathrm{rpm})$ for $10 \mathrm{~min}$ or let sit at room temperature for $2-3 \mathrm{~h}$.

4. Collect $2 \mathrm{~mL}$ of supernatant (lymphocyte layer/buffy coat), distribute to two to three T25 flasks or $15-\mathrm{mL}$ tubes and culture for $72 \mathrm{~h}$ at $37^{\circ} \mathrm{C}$ (shake flasks once a day).

5. Add two drops of colcemid $2 \mathrm{~h}$ before harvesting using a 24-gauze needle (stock: $10 \mu \mathrm{g} / \mathrm{mL}$ ).

6. Transfer to $15-\mathrm{mL}$ tubes and centrifuge for $5 \mathrm{~min}$ at $250 \mathrm{~g}(1500 \mathrm{rpm})$.

7. Remove supernatant and add $5 \mathrm{~mL}$ of prewarmed $\left(37^{\circ} \mathrm{C}\right) 0.56 \%$ hypotonic solutions (KCI) to each tube drop-by-drop, tapping tubes, and add more $\mathrm{KCI}$ to a total volume of $10 \mathrm{~mL}$.

8. Incubate at $37^{\circ} \mathrm{C}$ water bath for $15-20 \mathrm{~min}$.

9. Centrifuge for $5 \mathrm{~min}$ at $1500 \mathrm{rpm}(250 \mathrm{~g})$ and remove supernatant.

10. Add $2 \mathrm{~mL}$ of freshly prepared fixative (3 methanol: 1 acetic acid) per tube dropby-drop by tapping tubes.

11. Add more fixative to total $10 \mathrm{~mL} /$ tube and let sit at room temperature for $1-2 \mathrm{~h}$.

12. Centrifuge for $5 \mathrm{~min}$ at $1500 \mathrm{rpm}(250 \mathrm{~g})$ and remove supernatant. Repeat steps 11-12 for three times.

13. Resuspend in $1-2 \mathrm{~mL}$ of fixative each tube (adjust the cell concentration depending on the size of the pellet).

14. Drop suspension onto clean glass slides (dip slides in ethanol and wipe with a Kleenex tissue).

15. Check each batch of chromosome preparations for $\mathrm{CGH}$ and store at $4^{\circ} \mathrm{C}$. (see Note 2). 


\subsection{Preparation of Labeled DNA Probes for $\mathrm{CGH}$}

High-molecular weight genomic DNA from a normal donor (reference DNA) and a tumor (test DNA) is required for CGH. Several DNA extraction kits are available commercially for genomic DNA preparation (QIAGEN, Promega). Degraded DNA should be avoided because it will yield probes that are too small upon nick translation, thereby resulting in poor-quality CGH (see Note 3).

The DNA extracted from microdissected tumor cells can be used for CGH. However, the DNA isolated from these cells might be insufficient for CGH analysis. Several whole genome amplification methods are currently available to generate the large quantities of DNA that are required for CGH and other genome screening methods (12).

\subsubsection{Probe Labeling}

1. To label test or reference DNA by nick translation add the reagents in the following order:
a. $1 \mu \mathrm{g}$ Test DNA or reference DNA in $38 \mu \mathrm{L}$ dd $\mathrm{H}_{2} \mathrm{O}$.
b. $5 \mu \mathrm{L} 10 \mathrm{X}$ dNTP mix.
c. $1 \mu \mathrm{L}$ dTTP mix.
d. $1 \mu \mathrm{L}$ Fluorescein isothiocynate (FITC) or Texas Red.
e. $5 \mu \mathrm{L}$ Enzyme mix containing DNA polymerase I/DNase I.
f. $1 \mu \mathrm{L}$ DNA polymerase I.

2. Mix contents of the tube well and incubate at $15^{\circ} \mathrm{C}$ for $1 \mathrm{~h}$ and $45 \mathrm{~min}$. (The nick translation time needs to be adjusted depending on the size of the genomic DNA.)

3. Place tubes on ice, while keeping them protected from light.

4. Check the DNA fragment size by running a $1 \%$ agarose gel, using a $3-\mu \mathrm{L}$ aliquot of the reaction.

5. Remove unincorporated nucleotides by running through a Sephadex G-50 column.

6. If fragment size is in the appropriate range (500- to 3000-bp), heat the tubes at $75^{\circ} \mathrm{C}$ for $10 \mathrm{~min}$, to inactivate the enzymes (see Note 4 ).

\subsubsection{DNA Purification}

1. Allow the G-50 Sephadex column to warm up to room temperature. Gently invert it several times to resuspend the medium, while flicking it to remove any air bubbles.

2. Remove the top cap from the column, followed by the bottom tip. This sequence is absolutely necessary to avoid creating a vacuum, and uneven flow of buffer. Place on a collection tube. Allow the buffer to drain by gravity and then discard the elute.

3. Place the column and collection tube in a $15-\mathrm{mL}$ centrifuge tube, and centrifuge for $3 \mathrm{~min}$ at $3000 \mathrm{rpm}$ in a swinging bucket rotor. Discard the eluted buffer.

4. Keeping the column in an upright position, carefully apply the DNA sample to the center of the column bed.

5. Place the column on a second collection tube while keeping it in an upright position. Centrifuge for $3 \mathrm{~min}$ at $3000 \mathrm{rpm}$. Please note that speed and length of centrifugation should be calibrated for individual centrifuges.

6. Collect the elute from the collection tube. This contains the purified DNA sample. 


\subsubsection{Precipitation of Probe DNA for Hybridization}

1. Add $40 \mu \mathrm{L}$ FITC-labeled tumor DNA, $40 \mu \mathrm{L}$ Texas Red-labeled normal reference DNA, $20 \mu \mathrm{L}$ Human Cot-1 DNA, $10 \mu \mathrm{L} 3 M$ sodium acetate, and $400 \mu \mathrm{L}$ cold absolute ethanol.

2. Mix contents well and leave at $-70^{\circ} \mathrm{C}$ for at least $1 \mathrm{~h}$.

3. Centrifuge at $14,000 \mathrm{rpm}$ for $30 \mathrm{~min}$ at $4^{\circ} \mathrm{C}$.

4. Remove the supernatant. A good size pellet should be visible at the bottom of the tube.

5. Wash the pellet with $500 \mu \mathrm{L}$ cold $70 \%$ ethanol.

6. Centrifuge at $14,000 \mathrm{rpm}$ for $30 \mathrm{~min}$ at $4^{\circ} \mathrm{C}$.

7. Remove the supernatant as thoroughly as possible. Air-dry pellet in the dark for at least $2 \mathrm{~h}$, until completely dry.

8. Resuspend the pellet in $10 \mu \mathrm{L}$ hybridization mixture. Mix thoroughly by tapping the bottom of the tube several times. Allow the pellet to dissolve over 2-3 $\mathrm{h}$.

\subsubsection{Slide Pretreatment}

1. Pretreat all slides before use, for $1 \mathrm{~h}$ in $2 \mathrm{X} \mathrm{SSC}$ at $37^{\circ} \mathrm{C}$.

2. Rinse slides in distilled water.

3. Treat the slides in series of ethanol $(70,80$, and $100 \%$ absolute ethanol) for 2 min each. Air-dry slides (see Note 5).

\subsubsection{Slide Denaturation}

1. Place the slides in denaturation solution (see Subheading 2.2., item 28) for $2 \mathrm{~min}$ in a $74^{\circ} \mathrm{C}$ water bath in a Coplin jar. Denature only two slides at a time.

2. After denaturation, immediately place the slides in ice cold $70 \%$ ethanol. Wash the slides in 70, 80, and 100\% ethanol for 2 min each. Air-dry the slides.

\subsubsection{Probe Denaturation and Hybridization to Target Chromosomes}

1. Denature the probe in a $74^{\circ} \mathrm{C}$ water bath for $6 \mathrm{~min}$.

2. Upon removal from the water bath, immediately apply the probe onto the slide and place a $22-\mathrm{mm}^{2}$ cover slip over the probe.

3. Seal the edges of the cover slip with rubber cement. Up to two different hybridizations can be done on one slide, using half of the slide for each probe. It is useful to note that, sealing the middle of the slide first will prevent the cover slip from moving when applying the rubber cement.

4. Place the slides in a humidified chamber (Tupperware with paper towels moistened with formamide solution). Incubate the slides at $37^{\circ} \mathrm{C}$ for $48 \mathrm{~h}$.

\subsubsection{Posthybridization Washes}

1. Prewarm $50 \%$ formamide/2X SSC, 2 X SSC, and $0.1 \%$ SSC in a $45^{\circ} \mathrm{C}$ water bath.

2. Remove slides from the humid chamber and carefully remove rubber cement and cover slips from the slide.

3. Wash in $50 \%$ formamide/2X SSC for 10 min shaking intermittently. 

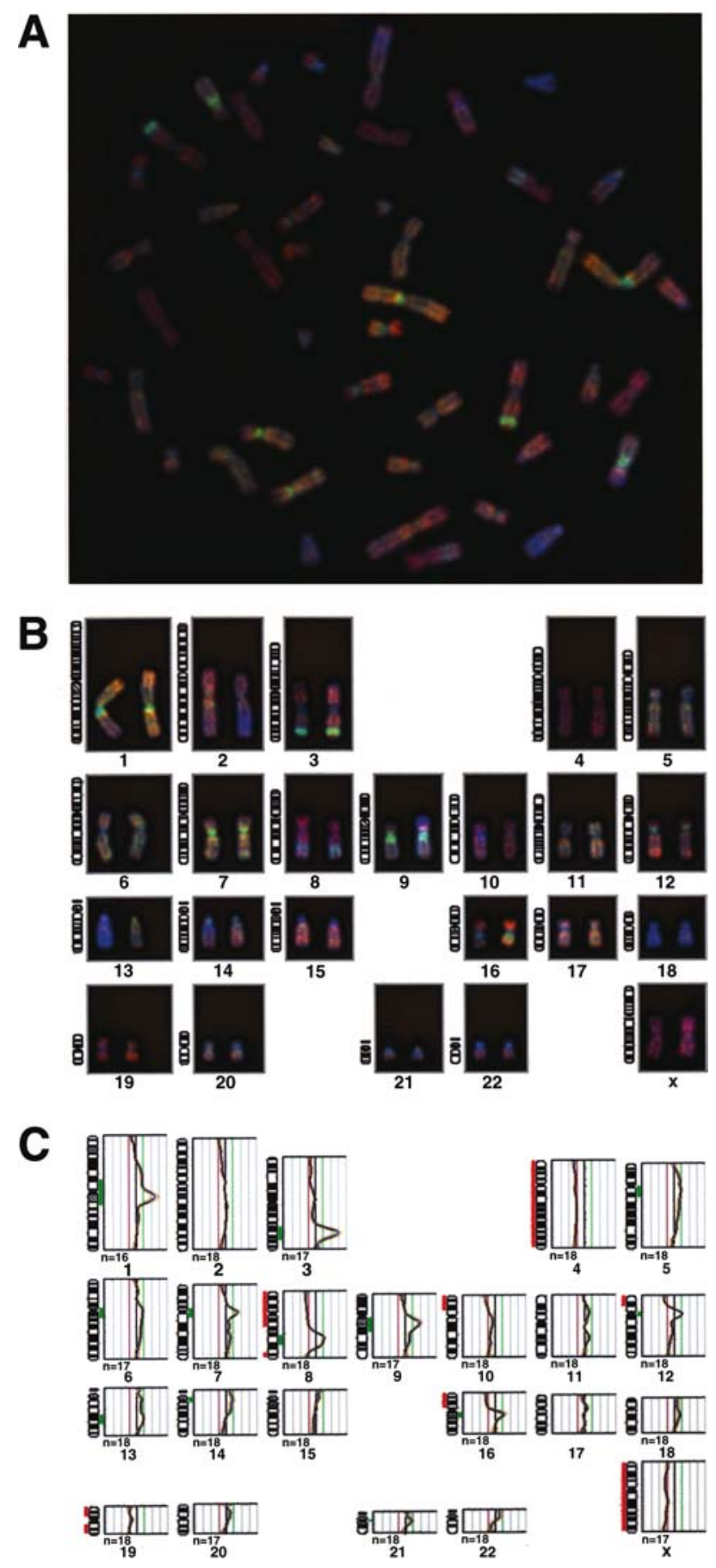
4. Wash twice in $2 \mathrm{X} \mathrm{SSC}$ for 5 min each.

5. Wash once in $0.1 \mathrm{X} \mathrm{SSC}$ for $5 \mathrm{~min}$.

6. Wash slides once in $1 \mathrm{X}$ PN buffer for $5 \mathrm{~min}$ at room temperature.

7. Rinse in distilled water. Air-dry slides in the dark.

8. Apply $20 \mu \mathrm{L}$ DAPI/antifade across the slide.

9. Cover the slide with a $24 \times 50-\mathrm{mm}^{2}$ cover slip.

\subsubsection{Microscopy and Image Analysis for $\mathrm{CGH}$}

1. A fluorescence microscope equipped with a CCD camera and appropriate filters (DAPI, fluorescein, and Texas Red or rhodamine) is required to visualize metaphase spreads hybridized with differentially labeled test and reference DNA (Fig. 1A). The differences in the relative intensities of the two fluorochromes can provide a color ratio profile indicative of copy-number changes in the test DNA relative to the reference DNA. The following criteria is essential for highquality $\mathrm{CGH}$, (1) well spread metaphase chromosomes with adequate length, (2) uniform red and green hybridization (no granularity), (3) the red and green fluorescence distribution should be similar between two sister chromatids, two homologous chromosomes and the same chromosome in all the metaphases, (4) good DAPI banding for the identification of chromosomes, and (5) background fluorescence level surrounding the chromosomes should be low and uniform.

2. After direct visual inspection, the metaphase chromosomes are subjected to quantitative analysis. This type of analysis can only be derived from digital imaging. Several digital imaging systems are available commercially for CGH analysis (Applied Imaging [San Jose, CA], Applied Spectral Imaging, Leica Microsystems Inc. [Bannockburn, IN], and Metasystems [Watertown, MA]). By digital imaging, first individual chromosomes will be segmented, local background subtracted, and the median axises of the chromosome defined $(\mathbf{1 3 , 1 4 )}$. These chromosomes will then be normalized to standard length and combined,

Fig. 1. (Opposite page) Comparative genomic hybridization analysis. (A) A metaphase spread after simultaneous hybridization with differentially labeled normal (red) and tumor (medulloblastoma in this case) DNA (green) by CGH. Chromosomal regions that were over-represented in the tumor are visualized in green, whereas regions that were lost or deleted from the tumor are seen as red color. (B and C). Quantitative analysis of CGH. (B) Chromosomes from Fig. 1A identified and karyotyped using quantitative imaging processing software (QUIPS, Applied Imaging). (C) Quantitative digital image analysis of fluorescence intensity ratios. Green to red fluorescence ratio profiles is shown for all chromosomes. The mean ratio (blue line) and \pm 1 SD (black lines) of 13-20 measurements for each chromosome are shown. The ratio profiles for each chromosome are shown from pter to qter. The average value (1) representing the mean green to red ratio for the entire case (6-10 metaphases) and red and green lines indicate threshold values of 0.8 and 1.2 for loss and gain, respectively. 
a minimum of 10 chromosomes to show statistically the mean and 95 or $99 \%$ confidence intervals of the red: green signal ratio. Control experiments (normal vs normal DNAs) are very helpful for interpretation of CGH results from tumor samples with a particular batch of slides and reagents. Only ratio changes that exceed the fluctuation seen in the control experiments are interpreted as evidence for real loss or gain in the tumor compliment (Fig. 1B,C). The normal variation in a given CGH experiment should not exceed ratios of 0.80-1.20 ( \pm 1 SD). In most cases, the telomeric, peri-centromeric or heterochromatic regions fall outside this range due to low signal intensities. Therefore, these regions should be excluded from the analysis. In addition, caution should also be exercised in interpreting ratio changes at 1p32-p36, 16p, 19, and 22 because of the high abnormal ratios in these regions. Chromosomal amplifications can be detected as strong localized FITC signal at the chromosomal site. For the precise assignment of amplification to chromosomal bands, the peak of the ratio profile should be compared with corresponding DAPI band of the same chromosome.

\subsection{Tumor Chromosome Preparations for SKY and FISH}

The investigation of karyotypic changes in tumor cells requires ability to arrest cells at the metaphase stage, achieve spreading of the chromosomes to finally study them under a microscope using an array of conventional and molecular cytogenetics methods. Essentially, it is feasible to prepare chromosomes from any actively dividing tumor cells. Conventional karyotypic examination requires preparation of metaphases and staining by banding methods to enable identification of individual chromosomes. Although there are a number of techniques used for the recognition of specific chromosomal structures or regions, the G-banding method has been the most accepted technique. Owing to limitation of space it is recommended that the reader refer to standard methods $(15,16)$.

\subsection{Spectral Karyotyping}

Conventional karyotype analysis is one of the widely accepted genomescreening tools for identification of chromosomal aberrations in cancer cells. However, metaphases with poor morphology and complexly rearranged marker chromosomes, a common feature of tumor cells, are often difficult to interpret unambiguously. The advent of multicolor FISH methods provides new ways to identify precisely the nature of complex chromosome changes $(4,5)$. This method is based on the hybridization of combinatorially labeled chromosomespecific painting probes to metaphase spreads, allowing simultaneous visualization of each chromosome pair by a unique color, in a single experiment. The principle of multicolor FISH lies in labeling individual whole chromosome probe pools in different fluorochromes or different ratios of fluorochromes such that each chromosome ultimately displays a distinct color. Two distinctly 

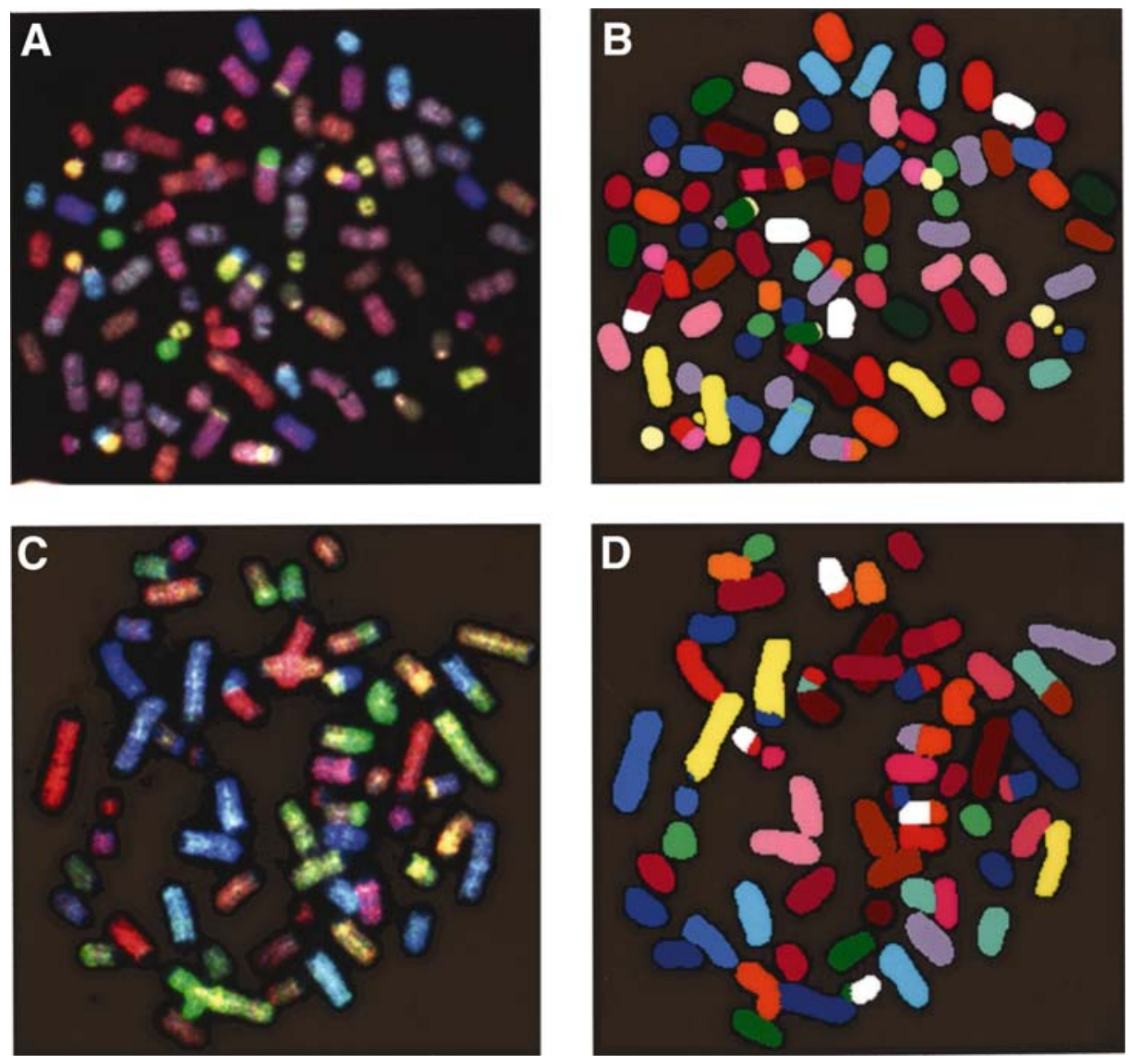

Fig. 2. SKY images of metaphase chromosomes from human (A and $\mathbf{B})$ and mouse (C and D) tumors with complex chromosomal rearrangements. (A and C) Spectra-based display colors, (B and D) spectral classification from the same metaphase spreads.

different protocols have been developed for further analysis. One, termed multiplex FISH (m-FISH) (4), makes use of digital images acquired separately for each of five fluorochromes employed in labeling probes. The images are acquired by use of appropriate filters and a CCD camera and analyzed by dedicated software that generates a composite image in which each chromosome is pseudo-colored on the basis of the composition of fluorochrome(s) used. The other procedure is SKY (5), which makes use of an entirely different system of image acquisition from the probe-hybridized metaphase, which combines CCD imaging with Fourier spectroscopy. The images are analyzed by dedicated software, which generates composite images as in the case of m-FISH (Fig. 2). The power of these new labeling and image acquisition/analysis techniques in the 
definition of chromosomal changes in cancer cells are manifold. Thus, chromosomal breakpoints can be mapped and the composition of marker chromosomes determined with high precision. However, the breakpoint determination on painted chromosomes/inverted DAPI is often difficult mainly owing to the poor chromosomal morphology after hybridization. Therefore, G-banded karyotypes from the same tumor will be useful in determining breakpoints.

\subsubsection{Slide Pretreatment}

1. Prepare chromosome spreads and mark the area of hybridization target with a diamond pencil.

2. Equilibrate the slides with $2 \mathrm{X}$ SSC for $30 \mathrm{~min}$ at RT.

3. Rinse the slides in distilled water.

4. Dehydrate the slides in series of ethanol (70, 80, and $100 \%$ absolute ethanol) for 2 min each. Air-dry slides.

5. Slides that appear particularly cytoplasmic should undergo pepsin treatment.

6. Prewarm $50 \mathrm{~mL}$ of $0.01 \mathrm{M} \mathrm{HCl}$ in a Coplin jar at $37^{\circ} \mathrm{C}$. Add 5-25 $\mu \mathrm{L}$ of pepsin stock solution and mix well. Incubate slides at $37^{\circ} \mathrm{C}$ in a Coplin jar for $5-10 \mathrm{~min}$.

7. Wash slides in $1 \mathrm{X}$ PBS for 5 min at RT. Repeat the wash a second time in PBS.

8. Wash slides in $1 \mathrm{X} \mathrm{PBS} / \mathrm{MgCl}_{2}$ for $5 \mathrm{~min}$ at RT.

9. Incubate slides in $1 \%$ formaldehyde in $1 \mathrm{X} \mathrm{PBS} / \mathrm{MgCl}_{2}$ for $10 \mathrm{~min}$ at RT.

10. Wash slides in $1 \mathrm{X}$ PBS for $5 \mathrm{~min}$ at RT.

11. Dehydrate the slides in a series of 70,80, and $100 \%$ absolute ethanol for 2 min each. Air-dry slides (see Notes 7 and 8).

\subsubsection{Slide Denaturation}

1. Place the slides in denaturation solution (70\% formamide/2X SSC) for $2 \mathrm{~min}$ in a $74^{\circ} \mathrm{C}$ water bath. Denature not more than two slides at a time.

2. After denaturation, immediately place the slides in ice cold $70 \%$ ethanol. Pass slides through 70, 80, and $100 \%$ ethanol for 2 min each. Air-dry the slides.

\subsubsection{Probe Denaturation and Hybridization to Target Chromosomes}

1. Denature the sky paint mixture in a $78-80^{\circ} \mathrm{C}$ water bath for $7 \mathrm{~min}$ and incubate in a water bath at $37^{\circ} \mathrm{C}$ for $1 \mathrm{~h}$.

2. Upon removal from the water bath, immediately apply the probe onto the slide and place a $22-\mathrm{mm}^{2}$ cover slip over the probe.

3. Seal the edges of the cover slip with rubber cement.

4. Place the slides in a humidified chamber (Tupperware with paper towels moistened with formamide solution).

5. Incubate the slides at $37^{\circ} \mathrm{C}$ for $48 \mathrm{~h}$.

\subsubsection{Posthybridization Washes}

1. Prewarm $50 \%$ formamide/2X SSC, $1 \mathrm{X} \mathrm{SSC}$, and $4 \mathrm{X}$ SSC/0.1\% Tween-20 in a $45^{\circ} \mathrm{C}$ water bath. 
2. Remove the slides from humid chamber and carefully remove rubber cement and cover slips from the slide.

3. Wash twice in $50 \%$ formamide $/ 2 \mathrm{X} \mathrm{SSC}$ for $10 \mathrm{~min}$ each at $45^{\circ} \mathrm{C}$.

4. Wash twice in $1 \mathrm{X} \mathrm{SSC}$ for $5 \mathrm{~min}$ each at $45^{\circ} \mathrm{C}$.

5. Wash once in $4 \mathrm{X} \mathrm{SSC} / 0.1 \%$ Tween-20 for $5 \mathrm{~min}$ at $45^{\circ} \mathrm{C}$.

6. Rinse in distilled water at room temperature.

\subsubsection{Detection}

1. Take the slides out of the distilled water and drain well. Add $60 \mu \mathrm{L}$ of vial no. 3 (supplied by ASI) over the specimen area and add a plastic cover slip. Place slides in a humidified chamber and incubate at $37^{\circ} \mathrm{C}$ for $30 \mathrm{~min}$. Adding blocking reagent prior to this step is optional.

2. Wash slides three times in $4 \mathrm{X}$ SSC/0.1\% Tween-20 for 5 min each.

3. Repeat step 1 with vial no. 4 (supplied by ASI) and incubate for $30 \mathrm{~min}$ in a humidified chamber at $37^{\circ} \mathrm{C}$.

4. Wash the slides three times in $4 \mathrm{X} \mathrm{SSC} / 0.1 \%$ Tween-20 for 5 min each.

5. Rinse the slides with distilled water for 2-3 min and air-dry the slides.

6. Place $15-20 \mu \mathrm{L}$ of DAPI in antifade over the hybridized area and add a cover slip of appropriate size. Now the slides are ready for capturing and analysis.

\subsubsection{Microscopy and Image Analysis for SKY}

SKY is based on spectral imaging, which is a combination of spectroscopy and imaging. In contrast to conventional epifluorescence microscopy in which flurochrome discrimination is based on the measurement of a single intensity through fluorochromes with a specific optical filter, spectral imaging allows one to measure and analyze the full spectrum of light at all given pixels of the image. These images can be captured and analyzed using hardware and software developed by applied spectral imaging (ASI).

\subsection{Fluorescence In Situ Hybridization}

FISH is a powerful molecular cytogenetic method based on the hybridization of specific nucleic acid sequences to the target genome (8). The DNA or RNA sequences are first labeled with reporter molecules and later the probe and the target, for example, chromosomes or nuclei are denatured. Complimentary sequences in the probe and target are then allowed to reanneal. After washing and incubation in fluorescently labeled affinity reagents, a discrete fluorescent signal is visible at the site of probe hybridization. An alternate method for labeling is the use of direct fluorochromes that incorporate into the DNA. This method does not require additional steps for detecting labels with fluorochrome-conjugated secondary agents. Several reporter molecules, for example, red (Texas Red, Spectrum Red, Cy 3) and green (FITC, Spectrum Green), are available for direct labeling of DNA. Multicolor in situ hybridization is relatively new method, in 

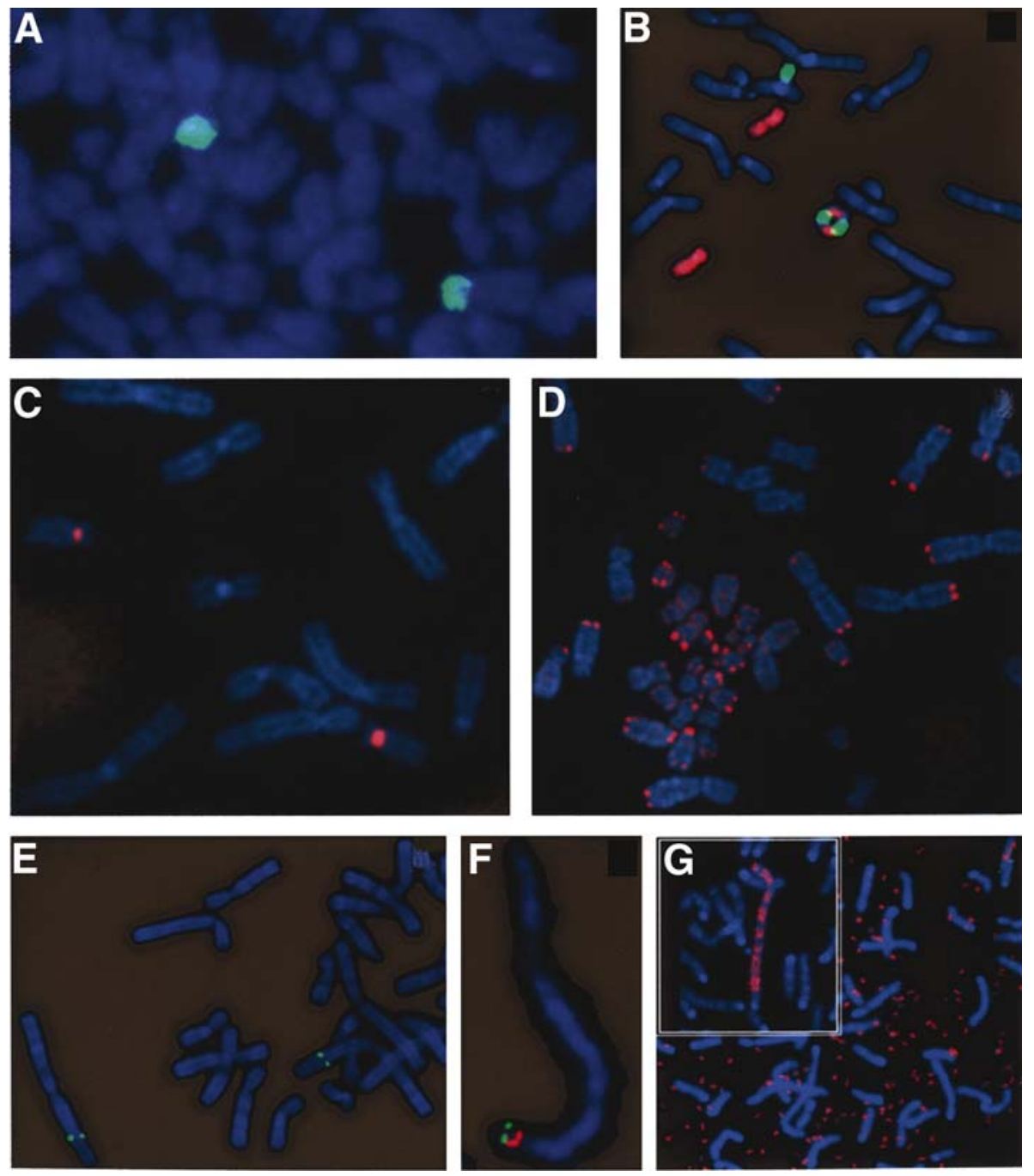

Fig. 3. Partial metaphase spreads showing examples of hybridization of various types of FISH probes. (A) A chromosomal arm probe (12p) labeled with Biotin and hybridized to normal human metaphase chromosomes, (B) A complex ring chromosome in a case of malignant fibrous histocytoma. Whole chromosome painting probes-WCP 17 (SpectrumOrange) and WCP 22 (SpectrumGreen) hybridized to metaphase spreads derived from a malignant fibrous histiocytoma, (C) Alpha satellite probe for chromosome 18 labeled with SpectrumRed hybridized to normal human metaphase chromosomes, (D) Cy 3-labeled peptide nucleic acid (PNA) telomeric FISH probe hybridized to human tumor chromosomes, (E) SpectrumGreen labeled single copy DNA probe hybridized to human chromosome 1p31 region, (F) Biotin and dioxigenin labeled single copy DNA probes hybridized to human pachytene chromosome 6, 
Table 2

Comparison of Sensitivity of Various FISH Mapping Techniques

\begin{tabular}{ll}
\hline Source & Resolution \\
\hline Metaphase chromosomes & $>1 \mathrm{mb}$ \\
Mechanically stretched chromosomes & $>200 \mathrm{~kb}$ \\
Pachytene chromosomes & $\sim 380-500 \mathrm{~kb}$ \\
Interphase nuclei & $\sim 50-\mathrm{kb}-1 \mathrm{mb}$ \\
DNA fibers & $\sim 1-500 \mathrm{~kb}$ \\
\hline
\end{tabular}

which several DNA probes can be labeled using different fluorochromes. This method is based on the availability of fluorochromes, optical filters, and image acquisition and registration software. Nick translation is the most common method for the labeling of DNA probes. However, it is useful to label small cDNA probes using the random priming method. Several DNA probes are commercially available that include chromosome-specific repeats (centromeric and telomeric), whole chromosome painting probes (WCP), chromosome arm probes, and single-copy sequences (human DNA sequences cloned in plasmid, phage, cosmid, PAC, bacterial artificial chromosome [BAC], yeast artificial chromosome vectors [YAC]) (Fig. 3). The relative position and orientation of clones along the chromosomal axis can be visualized and quantified by FISH. The wide array of currently available FISH techniques extends the resolution of visual mapping from a few megabases to only a few kilobases $(9,17)$ (Table 2).

\subsubsection{Preparation of Plasmid, Phage, Cosmid, PAC, and BAC DNA for FISH}

The DNA from any of the cloning vectors can be extracted using standard alkaline lysis protocols or a Qiagen (Valencia, CA) plasmid purification kit.

\subsubsection{Preparation of Labeled DNA Probes for FISH (Probe Labeling)}

1. To label Plasmid/Phage/Cosmid/PAC/BAC DNA by nick translation add the reagents in the following order:

a. $1 \mu \mathrm{g}$ DNA in $\mathrm{ddH}_{2} \mathrm{O}$ (make up to $50 \mu \mathrm{L}$ of total reaction volume).

b. $5 \mu \mathrm{L} 10 \mathrm{X}$ dNTP mix.

c. $1 \mu \mathrm{L}$ dTTP mix.

d. $1 \mu \mathrm{L}$ Spectrum Green or Spectrum Red.

e. $5 \mu \mathrm{L}$ Enzyme mix containing DNA polymerase I/DNase I.

Fig. 3. (Continued) (G) Identification of gene amplification in mouse breast cancer model. A BAC clone containing the Met gene labeled with SpectrumOrange and hybridized to metaphase chromosomes derived from mouse breast cancer cells. Multiple copies of double min are shown. Inset shows homogenously stained region with multiple copies of Met gene. 
2. Mix contents of the tube well and incubate at $15^{\circ} \mathrm{C}$ for $1 \mathrm{~h}$ and $45 \mathrm{~min}$. (The nick translation time can be adjusted depending upon the size of the genomic DNA. The bigger the probe the longer the requirement of incubation time.)

3. Place tubes on ice, while keeping them protected from light.

4. Check the DNA fragment size by running a $1 \%$ agarose gel, using a 2 - to $3-\mu \mathrm{L}$ aliquot of the reaction.

5. Heat the tubes at $75^{\circ} \mathrm{C}$ for $10 \mathrm{~min}$, to inactivate the enzymes (see Note 9 ).

\subsubsection{Precipitation of Probe DNA for Hybridization}

1. Add the following contents to the nick translation reaction mix before precipitation: a. $5 \mathrm{~mL}$ Human Cot-1 DNA (for YACs, BACs, and PACs to suppress the repetitive sequences).

b. $5 \mu \mathrm{L} 3 M$ Sodium acetate.

c. $300 \mu \mathrm{L}$ Cold absolute ethanol.

2. Mix contents well and leave at $-70^{\circ} \mathrm{C}$ for at least $1 \mathrm{~h}$.

3. Centrifuge at $14,000 \mathrm{rpm}$ for $30 \mathrm{~min}$ at $4^{\circ} \mathrm{C}$.

4. Remove supernatant. A good size pellet should be visible at the bottom of the tube.

5. Wash the pellet with $500 \mu \mathrm{L}$ cold $70 \%$ ethanol.

6. Centrifuge at $14,000 \mathrm{rpm}$ for $30 \mathrm{~min}$ at $4^{\circ} \mathrm{C}$.

7. Remove the supernatant as thoroughly as possible. Air-dry the pellet in the dark for at least $2 \mathrm{~h}$, or until completely dried.

8. Resuspend the pellet in $10 \mu \mathrm{LddH} \mathrm{H}_{2} \mathrm{O}$. Mix thoroughly by tapping the bottom of the tube several times. Allow the pellet to dissolve over $1 \mathrm{~h}$. When ready to carry out hybridization, prepare probe mixture by dissolving $2-3 \mu \mathrm{L}$ of labeled DNA in $10 \mu \mathrm{L}$ of hybridization mixture.

\subsubsection{Slide Pretreatment}

1. Pretreat all slides before use, for $1 \mathrm{~h}$ in $2 \mathrm{X} \mathrm{SSC}$ at $37^{\circ} \mathrm{C}$.

2. Rinse the slides in distilled water.

3. Treat the slides in 70, 80, and $100 \%$ absolute ethanol series for 2 min each.

4. Air-dry the slides. Please note that, metaphase spreads that appear particularly cytoplasmic should undergo pepsin treatment.

\subsubsection{Slide Denaturation}

1. Place the slides in denaturation solution (70\% formamide/2X SSC) for 2 min in a $74^{\circ} \mathrm{C}$ water bath. Denature a maximum of two slides at a time.

2. After denaturation, immediately place the slides in ice cold $70 \%$ ethanol. Wash the slides in 70, 80, and $100 \%$ ethanol for 2 min each.

3. Air-dry the slides.

\subsubsection{Probe Denaturation and Hybridization to Target Chromosomes}

1. Denature the probe in a $74^{\circ} \mathrm{C}$ water bath for 6 min.

2. Upon removal from the water bath, immediately apply the probe onto the slide and place a $22-\mathrm{mm}^{2}$ cover slip over the probe. 
3. Seal the edges of the cover slip with rubber cement.

4. Place the slides in a humidified chamber (Tupperware with paper towels moistened with formamide solution). Incubate the slides at $37^{\circ} \mathrm{C}$ for $24 \mathrm{~h}$.

\subsubsection{Posthybridization Washes}

1. Prewarm $50 \%$ formamide/2X SSC, 2 X SSC, and $0.1 \%$ SSC in a $45^{\circ} \mathrm{C}$ water bath.

2. Remove the slides from humid chamber and carefully remove rubber cement and cover slips from the slide.

3. Wash in $50 \%$ formamide/2X SSC for $10 \mathrm{~min}$.

4. Wash twice in $2 \mathrm{X} \mathrm{SSC}$ for $5 \mathrm{~min}$ each.

5. Wash once in $0.1 \mathrm{X} \mathrm{SSC}$ for $5 \mathrm{~min}$.

6. Wash the slides once in $1 \mathrm{X} \mathrm{PN}$ buffer for $5 \mathrm{~min}$ at room temperature.

7. Rinse in distilled water.

8. Air-dry the slides in the dark.

9. Apply $20 \mu \mathrm{L}$ DAPI/antifade across the slide.

10. Cover the slide with a $24 \times 50-\mathrm{mm}^{2}$ cover slip.

\subsubsection{Microscopy and Image Analysis for FISH}

A laboratory that focuses mainly on single copy gene mapping on interphase, metaphase or prophase chromosomes, a fluorescence microscope equipped with dual band pass filter or triple band pass filter for the simultaneous visualization of multiple probes or paints is required. Several digital imaging systems are available commercially for FISH/CGH, for example, Applied Imaging, Metasystems, Applied Spectral Imaging, and Leica.

\subsection{Future Perspective}

Our current awareness of chromosome abnormalities in cancers has permitted simultaneous detection of multiple abnormalities using multicolormultiplex FISH-type tests using the technologies described in this chapter. The combination of conventional and molecular cytogenetic methods of analyses will remain methods of choice in diagnosis and classification of malignant diseases into clinically and biologically relevant classes. With the availability of genome sequences of various organisms, including human, refined genome-wide screening approaches to define the cytogenetic changes such as microarray technologies will gain importance in both clinical and research scenarios. These technologies will ultimately provide personalized genetic diagnosis and treatment a reality.

\section{Notes}

1. Check the activity of DNase on normal DNA.

2. The quality of metaphase spreads is crucial for $\mathrm{CGH}$. The criteria for superior quality metaphase preparations include medium density, well spread, slight or no 
cytoplasm, and little debris on the slide. It is better to avoid chromosomes that appear bright or hollow. Sometimes synchronized chromosome preparations will give granularity on the chromosomes and this can adversely affect the fluorescence ratios.

3. The percentage of tumor cells in the specimen is critical for detecting chromosomal copy-number changes in cancer. If the tumor cell content in the tissue is less than $40 \%$, the resulting CGH karyotype will be normal. In those cases, the tumors' cells can be microdissected using laser capture microscope (Palm Laser-MicroBeam System, Wolfratshausen, Germany or Pix Cell II, Arcturus Biosciences, Inc., Mountain View, CA).

4. Optimum DNA fragment size is in the range of 500 to $3000 \mathrm{bp}$. If fragment size is larger than $3000 \mathrm{bp}$, continue the incubation for another 15-20 min after adding $1-2 \mu \mathrm{L}$ of a DNase working solution, if necessary.

5. Metaphase spreads that appear particularly cytoplasmic should be subjected to pepsin treatment.

6. CGH was the first high-throughput whole genome analysis methods for estimating DNA copy-number changes in the entire genome in a single experiment. Particular advantage of this method is that DNA from tumor specimens can be used to circumvent the need for tumor metaphases. CGH can be performed on good quality DNA isolated from any form of tissue, fresh, frozen, or archival.

7. The quality of metaphase spreads is crucial for SKY. The criteria for superior quality metaphase preparations include well spread, slight or no cytoplasm and little debris on the slide. It is better to avoid chromosomes that appear bright or hollow. The timing of pepsin treatment varies from sample to sample and therefore, it is better to evaluate pepsin digest placing a $24 \times 60-\mathrm{mm}^{2}$ cover slip under phase-contrast microscope. If excessive cytoplasm remain around the metaphase chromosomes, additional treatment with pepsin is necessary.

8. SKY on previously G-banded metaphase preparations is possible and the results obtained can be with similar hybridization intensities to slides that were not subjected to G-banding. Before doing SKY, the slides should go through xylene and methanol treatment. Previously G-banded chromosomes need a shorter denaturation time (15-30 s).

9. Optimum DNA fragment size is in the range of 100 to $500 \mathrm{bp}$. If fragment size is larger than $500 \mathrm{bp}$, continue the incubation for another 15-20 min after adding $1-2 \mu \mathrm{L}$ of a DNase working solution, if necessary.

\section{References}

1. Kallioniemi, A., Kallioniemi, O. -P., Sudar, D., et al. (1992) Comparative genomic hybridization for molecular cytogenetic analysis of solid tumors. Science 258, 818-821.

2. Rao, P. H., Cigudosa, J. C., Ning, Y., et al. (1998) Multicolor spectral karyotyping identifies new recurring breakpoints and translocations in multiple myeloma. Blood 92, 1743-1748. 
3. Singh, B., Gogineni, S. K., Sacks, P. G., et al. (2001) Molecular cytogenetic characterization of head and neck squamous cell carcinoma and refinement of $3 q$ amplification. Cancer Res. 61, 4506-4513.

4. Speicher, M. R., Ballard, S. G., and Ward, D. C. (1996) Karyotyping human chromosomes by combinatorial multi-fluor FISH. Nat. Genet. 14, 312.

5. Schrock, E., du Manoir, S., Veldman, T., et al. (1996) Multicolor spectral karyotyping of human chromosomes. Science 273, 494-497.

6. Pinkel, D., Segraves, R., Sudar, D., et al. (1998) High resolution analysis of DNA copy number variation using comparative genomic hybridization to microarrays. Nat. Genet. 20, 207-211.

7. Cai, W. W., Mao, J. H., Chow, C. W., Damani, S., Balmain, A., and Bradley, A. (2002) Genome-wide detection of chromosomal imbalances in tumors using BAC microarrays. Nat. Biotechnol. 20, 393-396.

8. Trask, J. B. (1991) Fluorescence in situ hybridization: applications in cytogenetics and gene mapping. TIG 7, 149-154.

9. Heiskanen, M., Peltonen, L., and Paloticm, A. (1996) Visual mapping by high resolution FISH. TIG 12, 379-382.

10. Sambrook, J., Fritsch, E. F., and Maniatis, T. (1989) Molecular Cloning, A Laboratory Manual, 2nd ed. Cold Spring Harbor Laboratory Press, New York.

11. Kallioniemi, O. P., Kallioniemi, A., Piper, J., et al. (1994) Optimizing comparative genomic hybridization for analysis of DNA sequence copy number changes in solid tumors. Genes Chromosomes Cancer 10, 231-243.

12. Lasken, R. S. and Egholm, M. (2003) Whole genome amplification: abundant supplies of DNA from precious samples or clinical specimens. Trends Biotechnol. 21, 531-535.

13. du Manoir, S., Kallioniemi, O. P., Lichter, P., et al. (1995) Hardware and software requirements for quantitative analysis of comparative genomic hybridization. Cytometry 19, 4-9.

14. Piper, J., Rutovitz, D., Sudar, D., et al. (1995) Computer image analysis of comparative genomic hybridization. Cytometry 19, 10-26.

15. Rooney, D. E. (ed.) (2001) Human Cytogenetics: Malignancy and Acquired Abnormalities. Oxford University Press, New York.

16. Verma, R. S. and Babu, A. (eds) (1995) Human Chromosomes: Principles and Techniques. McGraw-Hill, New York.

17. Hauptschein, R., Gamberi, B., Rao, P. H., et al. (1998) Cloning and mapping of human chromosome 6q26-27 deleted in B-cell non-Hodgkin's lymphoma and multiple tumor types. Genomics 50, 170-186. 